Review

\title{
The genetic audiogenic seizure hamster from Salamanca: The GASH:Sal
}

\author{
Luis J. Muñoz a,*, Melissa M. Carballosa-Gautam ${ }^{\text {b,c }}$, Kira Yanowsky ${ }^{\text {b, }}$ \\ Natividad García-Atarés ${ }^{\mathrm{d}}$, Dolores E. López ${ }^{\text {b,e }}$ \\ a Animal Research Service, University of Salamanca, 37007 Salamanca, Spain \\ ${ }^{\mathrm{b}}$ Institute for Neuroscience of Castilla y León/IBSAL, C/ Pintor Fernando Gallego, No. 1, 37007 Salamanca, Spain \\ c The Miami Project to Cure Paralysis, University of Miami Miller School of Medicine, 1095 NW 14thTerrace, Room 2-34, Miami, FL 33136, USA \\ d Department of Anatomy and Radiology, School of Medicine, University of Valladolid, 47007, Spain \\ e Department of Cell Biology and Pathology, University of Salamanca, Spain
}

\section{A R T I C L E I N F O}

\section{Article history:}

Received 30 July 2015

Revised 1 March 2016

Accepted 4 March 2016

Available online xxxx

\section{Keywords:}

AFLP

Animal mode

Audiogenic epilepsy

Audiogenic seizures

\begin{abstract}
A B S T R A C T
The hamster has been previously described as a paroxysmal dystonia model, but our strain is currently recognized as a model of audiogenic seizures (AGS). The original first epileptic hamster appeared spontaneously at the University of Valladolid, where it was known as the GPG:Vall line, and was transferred to the University of Salamanca where a new strain was developed, named GASH:Sal.

By testing auditory brainstem responses, the GASH:Sal exhibits elevated auditory thresholds that indicate a hearing impairment.

Moreover, amplified fragment length polymorphism analysis distinguished genetic differences between the susceptible GASH:Sal hamster strain and the control Syrian hamsters.

The GASH:Sal constitutes an experimental model of reflex epilepsy of audiogenic origin derived from an autosomal recessive disorder. Thus, the GASH:Sal exhibits generalized tonic-clonic seizures, characterized by a short latency period after auditory stimulation, followed by wild running, a convulsive phase, and finally stupor, with origin in the brainstem.

The seizure profile of the GASH:Sal is similar to those exhibited by other models of inherited AGS susceptibility, which decreases after six months of age, but the proneness across generations is maintained. The GASH:Sal can be considered a reliable model of audiogenic seizures, suitable to investigate current antiepileptic pharmaceutical treatments as well as novel therapeutic drugs.
\end{abstract}

This article is part of a Special Issue entitled Genetic Models-Epilepsy.

(c) 2016 Elsevier Inc. All rights reserved.

\section{Introduction}

Animal models for epilepsy are fundamental for studying epileptic disorders [1,2]. Although there is no single model of epilepsy that fully recapitulates the human disease spectrum, those models that are genetically predisposed to mimic the variable and complex genetic architecture of epilepsy have proven invaluable [3,4]. Notably, models susceptible to audiogenic seizures, which are genetically susceptible to sound-induced reflex seizures, have vastly contributed to the knowledge of this disease [5-8].

Audiogenic seizures (AGS) are generalized seizures that reproducibly occur with exposure to a high-intensity sound stimulus. Vasiliev described the first observations of this disorder in 1924 [9].

\footnotetext{
* Corresponding author at: Animal Research Service, University of Salamanca, 37007 Salamanca, Spain. Tel.: + 34 923294400x3011.

E-mail address: lmp@usal.es (L.J. Muñoz).
}

They are categorized as generalized seizures originating in the midbrain and provoked by high-intensity acoustic stimulation [10,11]. Several authors have attempted to identify the anatomical substrate responsible for the genesis and propagation of audiogenic seizures. Many point to the inferior colliculus as being directly responsible for seizure susceptibility because its ablation in rats and mice abolishes AGS permanently [12-14]. Furthermore, electrical and chemical stimulation of the inferior colliculus (IC) is observed to trigger a seizure [15].

Although the IC is suggested to be highly involved in generating AGS [16], the afferent peripheral system has been implicated also because it has a particular sensitivity to hyperstimulation during development. Additionally, AGS and priming models have demonstrated functional abnormalities within the auditory system [17]. Recently, our laboratory has detected alterations in the auditory pathway in the AGS hamster strain GPG:Vall, particularly in the olivocochlear neurons and the inner ear [18].

Susceptibility to AGS has been proposed to be a result of altered cerebral inhibitory mechanisms [19]. Epilepsies are associated with 
a disruption in amino acid metabolism, principally gammaaminobutyric acid (GABA) [20]. Furthermore, the convulsive action of certain hydrazides, which reduce glutamate decarboxylase activity, has prompted questions regarding whether some forms of epilepsy are due to faults in GABA metabolism. An early comparative study of healthy persons and patients with epilepsy did not explicitly reveal any mutations [21], but in recent years, the number of genes associated with epilepsy has been increasing, with eighty-one representative epileptic syndromes and familial seizures in which causal mutations were confirmed, listed in the Online Mendelian Inheritance in Man [4]. By contrast, morphological and biochemical studies conducted in rats have demonstrated an increase in GABA concentration, GABA-positive neurons, and total neuron count in the IC in some AGS rat models [22]. These results suggest that AGS models possess an abnormal GABAergic system. It is possible that this alteration is due to an increased disinhibition of excitatory neurons during exposure to a trigger sound $[23,24]$. On the other hand, a developmental period may exist during which the cochlea and its function are particularly vulnerable to hyperstimulation [25].

The administration of amino acids which act as inhibitory neurotransmitters (e.g., glycine and taurine), results in a suppression of AGS [26]. Although variations in glycine levels are not evident, deficits in taurine are well documented [27].

Audiogenic seizures manifest themselves in several animal species, including the dog, mouse, rabbit, rat, and chicken $[1,28,29]$. Of these species, the rat and mouse have been most prominently utilized for detailed AGS studies. The majority of existing rat and mouse lines possess a congenital susceptibility to the manifestation of AGS. This anomaly is not observed in other mammals and is strictly related to the auditory and motor development of these species. As such, various rodent lines initially thought to be "resistant" to AGS may be manipulated to manifest such seizures following intense acoustic stimulation during a "sensitive" or "critical" postnatal period [25]. This phenomenon of inducing AGS susceptibility is known as "priming" and was originally described by Henry in 1967 [30]. By contrast, rodent lines that demonstrate an innate susceptibility (congenital or hereditary) that does not require any priming sound exposure exist. Examples include the Krushinski Molodkina line [31], selected in the old Soviet Union; the genetically epilepsy-prone rat (GEPR), selected in the late 1950s at the University of Arizona [32]; the Wistar audiogenic rat (WAR) strain selectively inbred from a strain of AGS Wistar rats at the Ribeirão Preto School of Medicine at the University of São Paulo, Brazil [33]; and the DBA (dilute brown agouti coat color) mouse [34], among others [2,25].

Regarding the hamster, the first references from the literature alluding to its convulsive symptomology belong to Yoon et al.[35]. This strain was originally categorized as expressing reflex seizures and designated "sz" for seizure [36]. It was subsequently categorized as showing dystonia, and its designation was modified to "dtsz" [37].

The hamster genetically prone to epilepsy, GPG:Vall (GómezPalomo-Gómez, Valladolid), exhibited generalized tonic-clonic seizures, of brainstem origin $[38,39]$, in response to stimulation with sound of a frequency of $1-20 \mathrm{kHz}$ and an intensity of $60-80 \mathrm{~dB}$. Similar to what occurs in other animal lines with congenital epilepsy, susceptibility is inversely proportional to age [38] and is dependent on the sleep-wake cycle, on light and dark fluctuations, and on repeated sound exposure [40].

The GPG:Vall strain progressively lost fertility and is now extinct. Prior to that, some individuals were transferred to the University of Salamanca where a new strain was developed by means of a cross with a wild-type Syrian hamster (Mesocricetus auratus). The resulting line was a strain of golden hamsters, the GASH:Sal (genetic audiogenic seizure hamster, Salamanca), that express audiogenic seizures and are the subject of the current work, which aimed to further characterize the GASH:Sal.

\section{Material and methods}

\subsection{Experimental animals}

This study used 2 strains of Syrian hamsters (M. auratus): the AGSsusceptible GPG:Vall [22] provided by the University of Valladolid and the golden Syrian hamsters, Lak:LVG(SYR)BR, from Charles River, Barcelona, Spain. The animals were housed in the Animal Facility of the University of Salamanca and followed an ad libitum diet with type A03 and type A04 meals (Panlab, Barcelona, Spain). Housing was in European Union (EU) standard type III polycarbonate cages (Tecniplast, Buguggiate, Italy) in a controlled environment of 30-70\% humidity, $19-23^{\circ} \mathrm{C}$, and a light/dark cycle of $14 \mathrm{~h} \mathrm{light} / 10 \mathrm{~h}$ dark. A total of 4 GPG:Vall and 6 Lak:LVG(SYR)BR (Charles River, Barcelona, Spain) hamsters were used for the original parental crosses. The animals were handled according to the recommendations of the European Convention for the Protection of Experimental Animals (2010/63/EU), with the approval of the Animal Care and Ethic Committee of the University of Salamanca.

\subsection{AGS assessment and seizure analysis}

This study assessed both AGS susceptibility and seizure phases. The age for sound stimulations was established according to existing literature regarding the AGS model and was set as a chronological age paradigm of $30,45,60$, and 180 days. To avoid the influence of the circadian rhythm, all tests were performed at the same time of day.

The animals were placed in a cylindrical acrylic arena (height: $50 \mathrm{~cm}$, diameter: $37 \mathrm{~cm}$ ) and allowed to acclimate for $1 \mathrm{~min}$. The animals were then exposed to a continuous white noise of $0-18 \mathrm{kHz}$ and an intensity of 115 to $120 \mathrm{~dB}$, to induce audiogenic seizures. Exposure continued until the initiation of wild running or until $20 \mathrm{~s}$ had elapsed, whichever came first. The recorded sound was created using a high-pass filter ( $>500$ Hz, Bruel \& Kjaer \#4134 microphone and preamplifier \#2619), digitized at $44.1 \mathrm{kHz}$, and played by a computer-coupled amplifier (Fonestar MA-25T, Revilla de Camargo, Spain) and speaker (Beyma T2010, Valencia, Spain) located above the arena. For each trial, video recordings began $1 \mathrm{~min}$ prior to the sound exposure and continued until the animal recovered from the stupor.

Videos were processed using iMovie software. For each session, the characteristic progression of the motor seizure and kinetic-postural components, as well as their duration, was determined, based on our own observations and references from other audiogenic seizures in other strains $[41,42]$.

\subsection{Seizure-activating nuclei}

To obtain the best detail on the neuroanatomical structures implicated in seizure genesis, we analyzed c-fos expression in both GASH:Sal and control hamsters after 60 min of sound exposure. The animals were euthanized with pentobarbital $(60 \mathrm{mg} / \mathrm{kg})$ and perfused transcardially with $0.9 \%$ saline wash solution followed by $4 \%$ paraformaldehyde fixative solution. Following perfusion, $40-\mu \mathrm{m}$ coronal serial sections were processed for immunohistochemistry using similar procedures to those used in our previous studies of rats [43] and hamsters [44]. Briefly, the sections were washed and incubated in a rabbit anti-FOS sc-52 primary antibody solution (1:2500; Santa Cruz Biotechnology, Santa Cruz, CA, USA) diluted in TBS (Tris-buffered saline) for $24 \mathrm{~h}$ at $4^{\circ} \mathrm{C}$. The tissue was then washed and incubated with a goat biotinylated secondary anti-rabbit antibody. (1:200, \#BA-1000, Vector Labs) for $2 \mathrm{~h}$ at room temperature and finally visualized with the avidin-biotin-peroxidase complex procedure (Vectastain, Vector Labs) and histochemistry for peroxidase without heavy-metal intensification. For each brain, all sections were mounted on slides, dehydrated, and coverslipped. Brain specimens taken from control animals as well as from GASH:Sal animals were processed simultaneously using the same batch of solutions and incubation times, in order 
to minimize the variability in the visualization of immunoreactivity and DAB reaction product. Negative controls were not treated with primary antibodies, and this resulted in the complete absence of immunolabeling.

All sections were examined with an upright bright-field microscope (\#BX5; Olympus, Center Valley, PA, USA) equipped with a digital camera (SpotRt@; Diagnostic Instruments, Sterling Heights, MI, USA). Low-magnification images were taken for analysis of immunostained structures. The photomicrographs shown in the figures were processed with minor modifications in the brightness and contrast, and the tissuefree background was removed using Adobe Photoshop ${ }^{\circledR}$ (version 9.0; Adobe Systems Incorporated, San Jose, CA, USA); these photomicrographs were then assembled in Canvas 7.0 software following the stereotactic brain atlas for the golden hamster [45].

The densitometric analysis of the labeled structures was carried out with Image (version 1.42; Rasband, N.S., National Institutes of Health, Bethesda, Maryland, USA; http://rsb.info.nih.gov/ij).

The optical densities of sections immunostained for Fos protein were compared between groups, allowing us to associate an objective value with the immunostained intensity. With digitized images, we performed densitometric analysis of Fos immunoreactive sections by measuring the integrated optical density in that region (the product of the mean optical density and the studied area). To do this, we used a standardized protocol from our laboratory [46], which included sampling, calibrating the optical density imaging (at both the microscope and camera), measuring the immunostaining optical density of the IC in different rostrocaudal levels, and standardizing the results. With the obtained numerical data, a comparative analysis was performed between controls and the GASH:Sal through the application of the unpaired Student's t-test for independent samples and by obtaining the mean standard error of each group studied, with 2 degrees of freedom and a significance of $\mathrm{p} \leq 0.05$. Data are reported as the means \pm standard error.

\subsection{Auditory brainstem response (ABR)}

Audiometric testing was performed in the Non-Invasive Neurofunctional Evaluation Service of the Alberto Sols Biomedical Research Institute (CSIC, Madrid) according to the following protocol.

Auditory brainstem response testing was conducted in a soundattenuating chamber using a TDT evoked potential workstation (Tucker Davis Technologies, Alachua, FL, USA). To obtain the ABR, a hamster was anesthetized with an intraperitoneal injection of ketamine $(100 \mathrm{mg} / \mathrm{kg})$ and xylazine $(10 \mathrm{mg} / \mathrm{kg})$, and subdermal electrodes were inserted in the vertex (reference electrode), midline between the two ears (active), in the mastoid region below the right ear (reference) and in the lumbar region (ground). A free-field Tucker Davis ES1 electrostatic speaker was positioned directly in front of the animal's ear at a fixed distance of $5 \mathrm{~cm}$.

Click and tone burst stimuli were generated with SigGen software (TDT). Click stimuli lasted $0.1 \mathrm{~ms}$ and were delivered at 30 pulses per second (pps). Tone burst ( 4 to $40 \mathrm{kHz}$ ) stimuli lasted $5 \mathrm{~ms}$ ( $2.5 \mathrm{~ms}$ for the rise and decay with no plateau) and were presented at $50 \mathrm{pps}$. Data were collected by a real-time processor (RP2, TDT) and analysed using BioSigRZ software (TDT). The biological signal was bandpass filtered $(1500,300 \mathrm{~Hz})$ and amplified with a four-channel preamplifier (RA4PA, TDT) with the artifact rejection level set at 99\% of the threshold relative to the maximum voltage input ( $10 \mathrm{~V}$ or input signal). The recording window was $10 \mathrm{~ms}$ in duration and was triggered by a timing pulse from the RP2 at the stimulus onset. Thresholds were determined by reducing the intensity of the stimulus in 10-dB steps until no latency-appropriate responses were evident. The intensity of the stimulus was then increased in 5- or 10-dB steps until a response could once again be discerned. Threshold was then defined as the lowest intensity at which a latency-appropriate response with an amplitude greater than 2 standard deviations above the mean background activity appears.

\subsection{Hereditary AGS susceptibility}

To study the possible hereditary transmission of AGS, a paradigm of crosses and backcrosses between male GPG:Vall and female golden Syrian hamsters was established. To determine the phenotype of each offspring and to classify it as susceptible or not susceptible, the auditory brain response (ABR) of each parent was measured. We first used the cross between a male GPG:Vall and a female Lak:LVG(SYR)BR to obtain the $F_{1}$ population. After $A B R$ testing of all animals, the integral members of this generation were crossed, and the $F_{2}$ descendants with the seizure phenotype were selected for further crossing. Additionally, trial backcrosses between susceptible $\mathrm{F}_{2}$ individuals and their corresponding parents were done to evaluate offspring phenotypes. The remaining offspring were further crossed between susceptible siblings. Susceptibility to AGS was determined for all offspring.

\subsection{Amplified fragment length polymorphism analysis}

The amplified fragment length polymorphism (AFLP) procedure, a highly sensitive method for detecting polymorphisms in DNA, has become widely used for the identification of genetic variation in strains. It was performed according to the method described by Vos et al. [47], with slight modifications for our study. The technique involves five steps: (I) digestion of the total cellular DNA using two different restriction enzymes, EcoRI and MseI; (II) ligation of the oligonucleotide adapters; (III) preamplification of EcoRI and Msel fragments with a combination of an EcoRI and MseI primer with one selective base each; (IV) a final amplification with additional selective nucleotides used in the EcoRI and MseI primers (Table 1); and (V) analysis of the amplified fragments using an automated DNA sequencer.

\subsubsection{Sampling}

For this study, two strains of Syrian hamsters (M. auratus) were used: 10 adult (3- to 7-month-old) control AURA hamsters (Janvier, Le Genest-Saint-Isle, France) and 12 adult (7- to 9-month-old) GASH: Sal hamsters originated in the Experimental Animal Facility of the University of Salamanca, Spain.

\subsubsection{DNA extraction}

Genomic DNA was extracted from whole blood using DNAzol ${ }^{\circledR}$ Genomic DNA Isolation Reagent (\#DN127, Molecular Research Center Inc., Cincinnati, OH, USA) and then purified, with the concentration being spectrophotometrically estimated with a Spectronic BioMate 3 (Thermo Fisher Scientific, Inc., Europe).

\subsubsection{AFLP analysis}

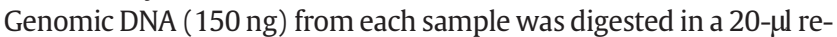
action volume consisting of the following: $1 \times$ REact I buffer (\#Y90002, Invitrogen, Carlsbad, CA, USA), EcoRI restriction enzyme (3.6 U) (\#R6011, Promega, Madison, WI, USA), and MseI restriction enzyme (4.0 U) (\#15494-016, Invitrogen). Following digestion, a 20- $\mu$ ligation mix consisting of 1.2 U T4 DNA ligase (\#M1801, Promega), $1.8 \mu \mathrm{M}$ EcoRI adapter (Isogen Life Sciences, Maarssen, Netherlands), $1.8 \mu \mathrm{M}$ MseI adapter (Isogen), and $1 \times$ ligase buffer containing $1.0 \mathrm{mM}$ ATP (\#C126, Promega) was added to each of the remaining 20- $\mu$ ldigested

\section{Table 1}

Number of animals used in this study in the different experimental approaches. Abbreviations: LVG(Lak)SYR, control Syrian hamster line from Charles River Laboratory; GASH:Sal, genetic audiogenic seizure hamster, Salamanca; GPG:Vall, Gómez-PalomoGómez genetically epilepsy-prone hamster, Valladolid.

\begin{tabular}{lcllll}
\hline $\mathrm{N}$ & $\begin{array}{l}\text { AGS } \\
\text { inheritance }\end{array}$ & $\begin{array}{l}\text { Seizure } \\
\text { analysis }\end{array}$ & ABR & Histology & AFLP \\
\hline Control: LVG(Lak)SYR & 2 & - & 8 & 2 & 10 \\
GASH:Sal & 133 & $22-81$ & 12 & 2 & 12 \\
GPG:Vall & 2 & - & - & - & - \\
\hline
\end{tabular}


DNA samples. The resulting mixture was quickly vortexed and stored overnight at $4{ }^{\circ} \mathrm{C}$. The product was diluted $1 / 5$ and used as the template for the subsequent preamplification reaction.

Preamplification with primers with the addition of a single selective nucleotide was performed in $25-\mu \mathrm{l}$ reaction volumes consisting of the following: $5 \mu \mathrm{l} 1 / 5$ diluted ligated DNA, $1 \times$ Colorless GoTaq ${ }^{\circledR}$ Reaction Buffer with $\mathrm{MgCl}_{2}$ (\#M792A, Promega), 0.2 mM dNTPs Mix (\#U1511, Promega), $0.3 \mu \mathrm{M}$ each of the EcoRI and MseI primers (Isogen), and 1.25 U GoTaq ${ }^{\circledR}$ DNA Polymerase (\#M3171, Promega). The PCR was run on a thermocycler (ABI7300, Applied Biosystems, Europe) under the following amplification conditions: one cycle ( 1 min at $\left.72{ }^{\circ} \mathrm{C}\right), 20-$ cycles ( $30 \mathrm{~s}$ at $94{ }^{\circ} \mathrm{C}, 1 \mathrm{~min}$ at $56{ }^{\circ} \mathrm{C}, 3 \mathrm{~min}$ at $72{ }^{\circ} \mathrm{C}$ ), and one cycle (5 min at $72{ }^{\circ} \mathrm{C}$ ). Selective amplification was performed in $25 \mu \mathrm{PCR}$ mix containing the following: $5 \mu \mathrm{l} 1 / 20$ diluted preamplification product, $1 \times$ buffer GoTaq ${ }^{\circledR}$ (\#M792A, Promega) with $\mathrm{MgCl}_{2}, 1.25 \mathrm{U}$ GoTaq ${ }^{\circledR}$ DNA Polymerase (\#M3171, Promega), $0.2 \mathrm{mM}$ dNTP mix (\#U151A, Promega), $0.5 \mu \mathrm{M}$ MseI primer, and $0.2 \mu \mathrm{M}$ EcoRI 6-FAMlabeled primer (Isogen). Six primer combinations were used (E32/ M48, E32/M58, E32/M60, E35/M48, E35/M58, and E35/M60). Primer sequences are shown in Table 2 . The PCR was run under the following conditions: one cycle $\left(2 \mathrm{~min}\right.$ at $\left.94^{\circ} \mathrm{C}\right), 13$ cycles [30 s at $94{ }^{\circ} \mathrm{C}, 1 \mathrm{~min}$ at $65{ }^{\circ} \mathrm{C}\left(0.7^{\circ} \mathrm{C}\right.$ decrease after each cycle $), 90 \mathrm{~s}$ at $\left.72{ }^{\circ} \mathrm{C}\right]$, and 25 cycles (30 s at $94{ }^{\circ} \mathrm{C}, 1 \mathrm{~min}$ at $56^{\circ} \mathrm{C}, 90 \mathrm{~s}$ at $72{ }^{\circ} \mathrm{C}$ ), and the final extension was carried out at $72{ }^{\circ} \mathrm{C}$ for $5 \mathrm{~min}$.

After selective amplification, $1.0 \mu \mathrm{l}$ of each PCR product was mixed with a volume of $9.0 \mu \mathrm{l}$ formamide and $1.5 \mu \mathrm{l}$ fluorescent ladder (60-400 bases, CXR, \#DG6221, Promega). Amplified fragment length polymorphism fragments were run on an ABI Prism 3100 Genetic Analyzer (Applied Biosystems, Foster City, USA) (Cancer Research Center, University of Salamanca, Spain). Following fragment separation, data files for each sample were created with GeneScan analysis software (Applied Biosystems) and Genotyper ${ }^{\mathrm{TM}}$ version 2.1 (Applied Biosystems). The data were imported into GeneMarker ${ }^{\circledR}$ software (Softgenetics LLC, PA, USA) and scored for each primer pair. Unambiguous polymorphic fragments, based on the standard parameter setting threshold, were scored as 1 for presence and 0 for absence to create a binary data matrix.

\subsection{Statistical analysis}

Statistical analysis of the seizure phase duration was performed using the SPSS software, version 18.0 (SPSS Inc., Chicago, IL, USA). All mean values were expressed \pm the standard error of the mean. Comparisons between groups were made by analysis of variance (mixed ANOVA split-plot), with pairwise comparisons Scheffe (between-subjects analysis) and Bonferroni post hoc test (intrasubject

Table 2

Enzymes and primers used for AFLP analysis.

\begin{tabular}{ll}
\hline EcoRI adapters & \\
Eco-ad-5 & 5'CTCGTAGACTGCGTACC3' \\
Eco-ad-3 & 5'ÁATTGGTACGCAGTCTAC3' \\
Msel adapters & \\
Mse-ad-5 & 5'GACGTAGAGTCCTGAG3' \\
Mse-ad-3 & 5'TACTCAGGACTCAT3' \\
Preamplification & \\
Eco-pre & 5'GACTGCGTACCAATTCA3' \\
Mse-pre & 5'GTAGAGTCCTGAGTAAC3' \\
Selective amplification & \\
EcoRI primers & \\
E32 & \\
E35 & 5'GACTGCGTACCAATTCA AC3 \\
Msel primers & 5'GACTGCGTACCAATTCA CA3' \\
M48 & \\
M58 & 5'GTAGAGTCCTGAGTAAC AC3' \\
M60 & 5'GTAGAGTCCTGAGTAAC GT3' \\
\hline
\end{tabular}

analysis). To compare differences between two means, we used Student's t-test taking into account Levene's test for equality of variances. Chi-square analysis was used to compare the percentage of animals expressing the seizure phenotype across each generation. The differences between groups were regarded as statistically significant when $\mathrm{p} \leq 0.05$.

For AFLP analysis, the GASH:Sal and control hamsters were considered to be different populations; also, because AFLP analysis produces multilocus dominant markers, the populations were assumed to be in Hardy-Weinberg equilibrium. Genetic diversity and population structure analyses were performed using the software AFLP-SURV [48]. Total gene diversity (HT), the average gene diversity among populations $(\mathrm{HB}=\mathrm{HT}-\mathrm{HW})[49]$, and the average gene diversity within the populations (HW) based on the approach of Lynch \& Milligan [50] and analogous to Nei's gene diversity [49] and Wright's fixation index (FST) [51] were calculated. The significance of FST was tested with 1000 random permutations. Dendrograms were constructed based on Nei's similarity coefficient [52] and the neighbor-joining method [53].

\section{Results}

\subsection{Clinical spectrum of seizures}

All AGS-susceptible animals exposed to the acoustic trigger had an initial latency period that was abruptly interrupted by wild running, occasionally accompanied by vocalization, urination, salivation, defecation, and falls. This phase progressed either directly into stupor, in which the crisis was incomplete, or continued as tonic-clonic seizures, characterized by the following kinetic-postural sequence:

- Opisthotonus, which entails hyperextension of the back, forelimbs, and tail; raised ears; and transversal spasms of the hindlimbs

- Generalized tonic-clonic seizures, which entail clonic seizures of the forelimbs and transversal tonic spasms of the hindlimbs

- Tonic opening and closing of the mouth, dorsoventral flexion of the neck and trunk, and tonic hyperextension of the forelimbs

- Hyperextension of the trunk and hindlimbs

- Occasional urination, defecation, vocalization, tremors, or testicular protrusion accompanying a seizure.

The seizures were classified according to the presence or absence of each phase as well as its duration for each time point $(30,45,60$, and 180 days of age). Seizure severity was scored according to existing scales or scores established in other rodent models $[41,42]$ and based on specific kinetic-postural attributes. These motor attributes recur at variable intervals and can be grouped into four grades from minor to major severity. Grade 1 is exclusively wild running. Animals categorized as grades II to IV (Fig. 1) exhibited a succession of tonic-clonic seizures that end in postictal stupor.

\subsubsection{Phase analysis}

At and below 30 days of age, the animals exhibit a shorter postictal stupor period and less severe seizures, which gradually increase through 2 months of age. At 45 days of age, the hamsters exhibited shorter latency periods, and the severity of the seizures also increased. At 60 days of age, hamsters exhibited the largest number of severe audiogenic seizures. At 6 months, hamsters exhibited only the wild running, and the seizures were relatively weak. Furthermore, the duration of the initial latency and stupor period reached their maxima (Figs. 2,3). The results are quantified for 80 hamsters from generations $F_{2}$ to $F_{8}$.

\subsection{Seizure-activating nuclei}

The inferior colliculus (IC) of GASH:Sal displayed strong immunoreactivity to the Fos protein following sound stimulation. The dorsal 


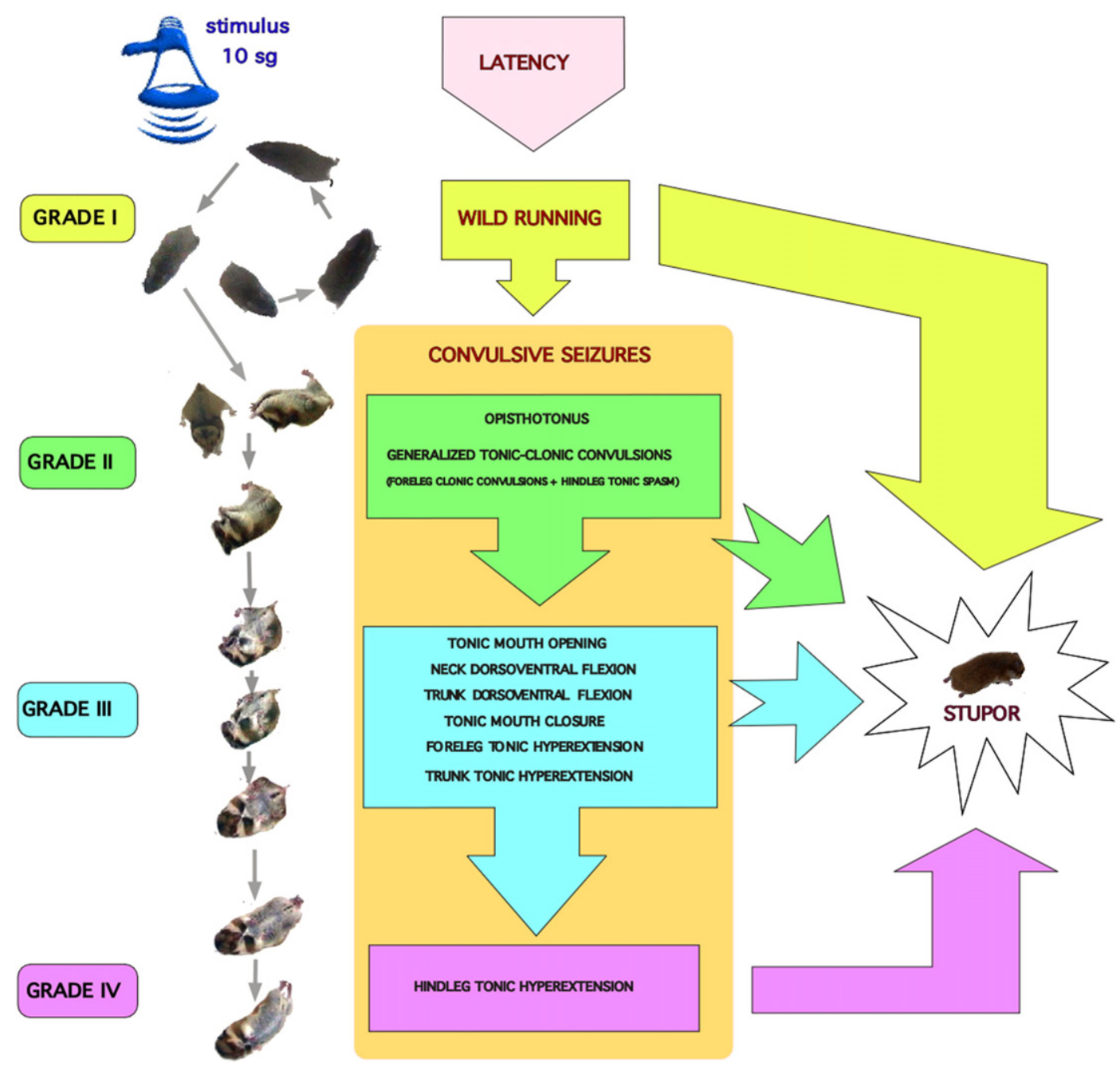

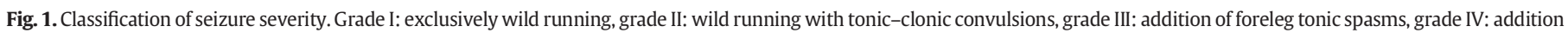
of hindleg tonic spasms.

(DCIC) and external (ECIC) cortices had the strongest immunoreactivity, whereas reactivity in the central nucleus (CIC) and intercollicular commissure, although present, was weaker.

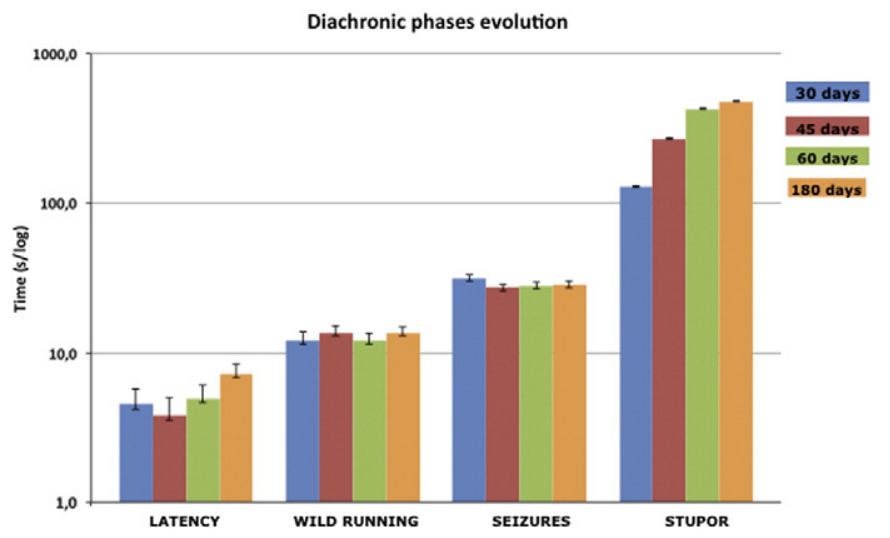

Fig. 2. Evolution of the durations of the different phases of the full seizure $(30,45,60$, and 180 days). Mean phase duration (in seconds, logarithmic scale). Mean duration (in seconds) of each phase. Maximum and minimum are represented by error bars (logarithmic scale). Number of animals in each age of evaluation $(30,45,60$, and 180 days of age): latency $(81,75,15,71)$, wild running $(74,73,18,72)$, seizures $(65,65$, $28,64)$, stupor $(23,23,4,21)$.
Immunoreactivity was also present in the periaqueductal gray (PAG). After the seizure, we also found positive immunoreactivity to Fos protein in other auditory nuclei, such as the lateral lemniscus and superior colliculus, but in lower intensity.

In Fig. 4, qualitative differences in immunostaining, when comparing the two experimental groups, can be seen, based on the topographical distribution of Fos immunoexpression.

Tissue sections were caudorostrally organized according to the stereotaxic atlas [45] and are illustrated in Fig. 5. To associate an objective value with the immunostaining intensity, we measured the optical density of the IC sections immunostained for Fos protein visualization. We normalized the results to a region having negative immunostaining, such as the middle cerebellar peduncle, in order to minimize any errors. The data used for analysis were those from the integrated optical density. These data indicate that the IC immunostaining of the GASH:Sal hamsters has greater Fos immunoexpression than the controls $(p<0.05)$, especially in the caudal areas, which is occupied mainly by the external cortex (Fig. 5). The same occurs, to an even greater extent, with the periaqueductal gray (data not shown).

\subsection{Auditory brainstem response}

Although the GASH:Sal hamsters displayed audiogenic seizures, they have profound deafness, with a threshold near $80 \mathrm{~dB}$. In fact, our results demonstrate that there is sound conductivity, but there is also 
Seizure severity grades

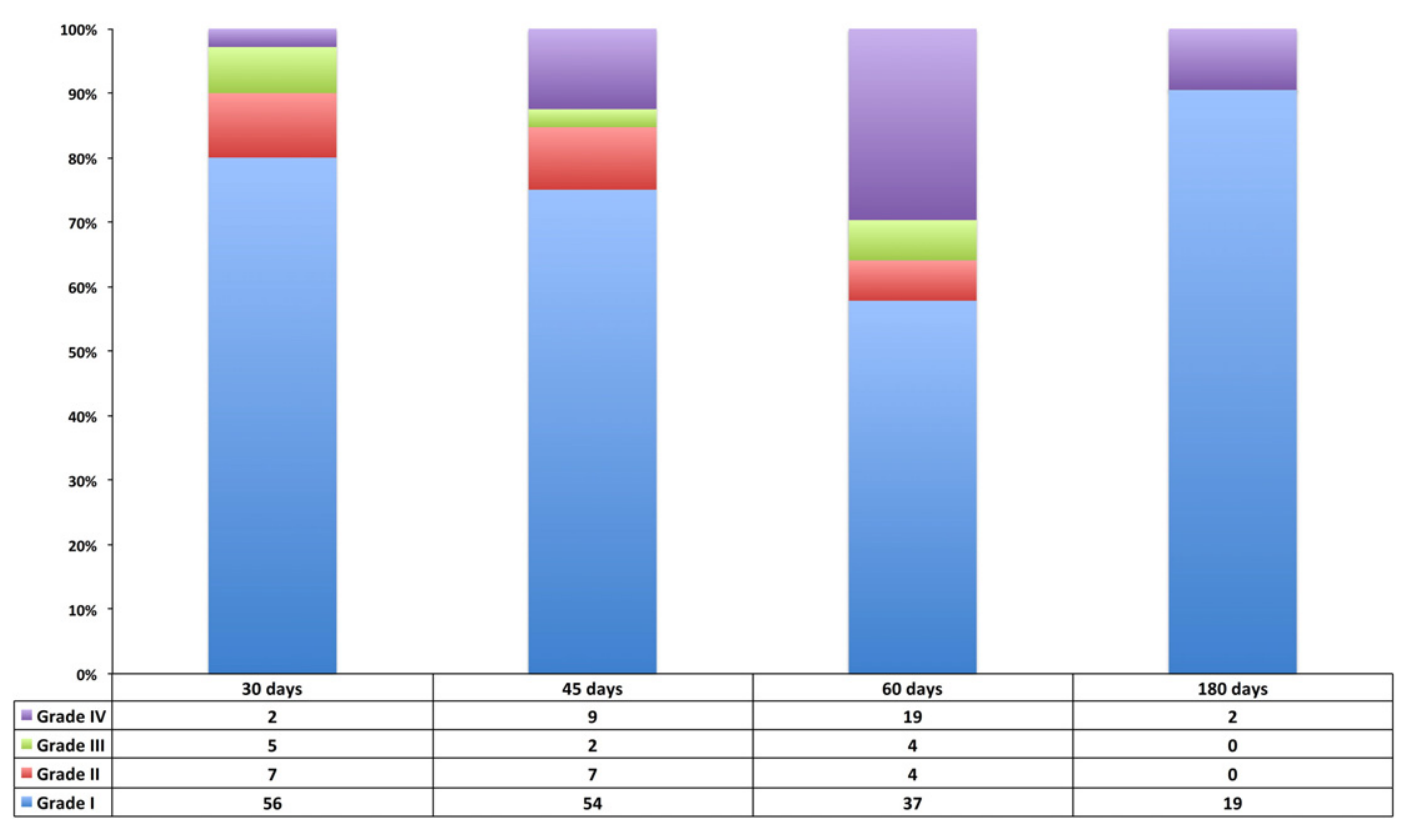

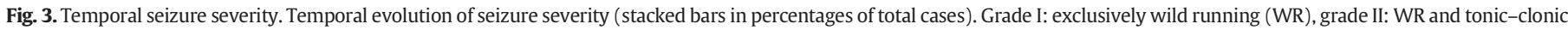
convulsion, grade III: tonic spasms of forelimbs, grade IV: tonic spasms of forelimbs and hindlimbs.

a significant hearing deficit, as seen in the reduction of response latencies (Fig. 6).

The audiogram was performed by determining the hearing threshold for a series of pure tones of $4-40 \mathrm{kHz}$. In control animals, audiograms are very similar in subjects at 3 to 9 months of age, with the best thresholds presented for frequencies of $4-16 \mathrm{kHz}$. In contrast, the GASH:Sal thresholds for the various frequencies are found to be relatively high at all ages. As such, to compare absolute and interpeak latencies between the GASH:Sal and controls, tests were performed using the maximum sound intensity of $90 \mathrm{~dB}$.

We calculated the latencies of the five characteristic peaks of the ABR record, as well as the interpeak latencies I-II, I-III, and I-IV after stimulation and have found that the absolute latencies of the peaks are higher for GASH:Sal animals at all ages even though there are no significant differences. Additionally, the interpeak latencies did not differ significantly between the two populations (Fig. 7).

\subsection{AGS as an inheritable disorder}

To establish a novel hamster model for epilepsy, selective breeding with two male GPG:Vall hamsters and two female Lak:LVG(SYR)BR hamsters successfully produced $18 \mathrm{~F}_{1}$ pups. No $\mathrm{F}_{1}$ pup was positive for seizure susceptibility. The cross with $\mathrm{F}_{1}$ siblings produced $105 \mathrm{~F}_{2}$ pups, of which 18 were susceptible to seizures. Backcrossing susceptible $F_{2}$ pups with $F_{1}$ produced 12 pups, of which 8 were susceptible. The null susceptibility of $F_{1}$ and the approximate $20 \%$ susceptibility of $F_{2}$ suggest an autosomal recessive pattern of inheritance. Chi-square testing

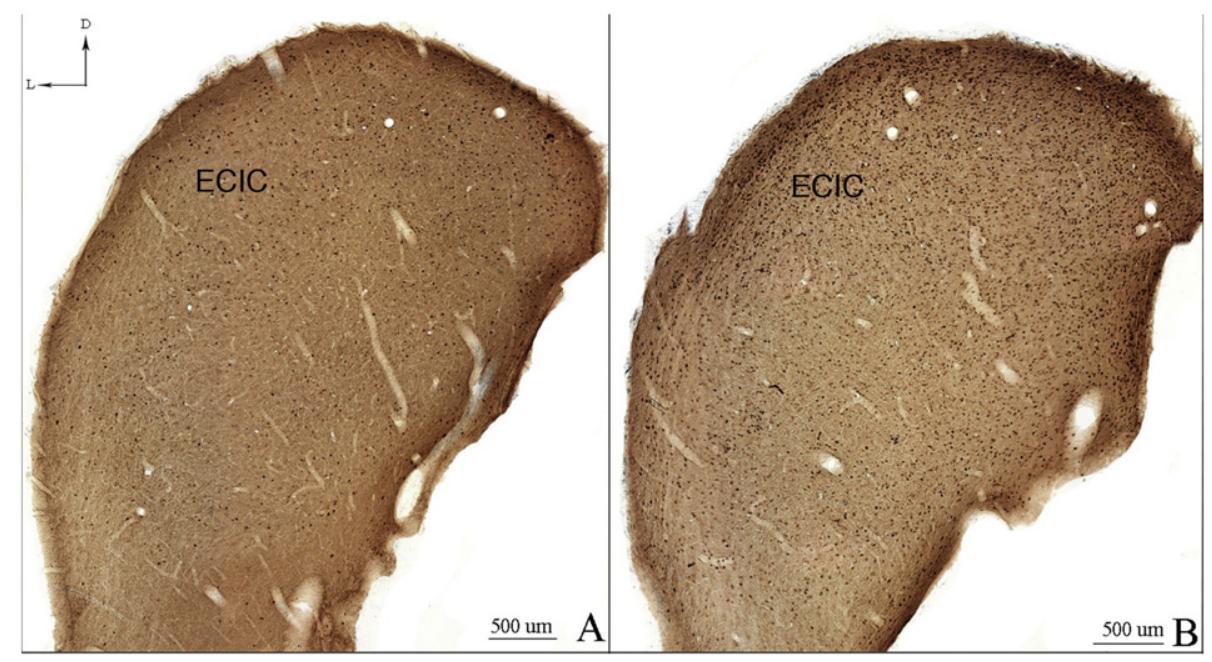

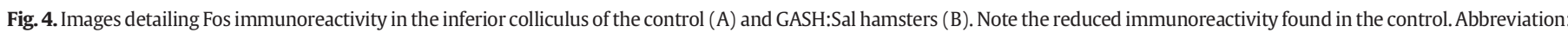
ECIC, external cortex of the inferior colliculus. 

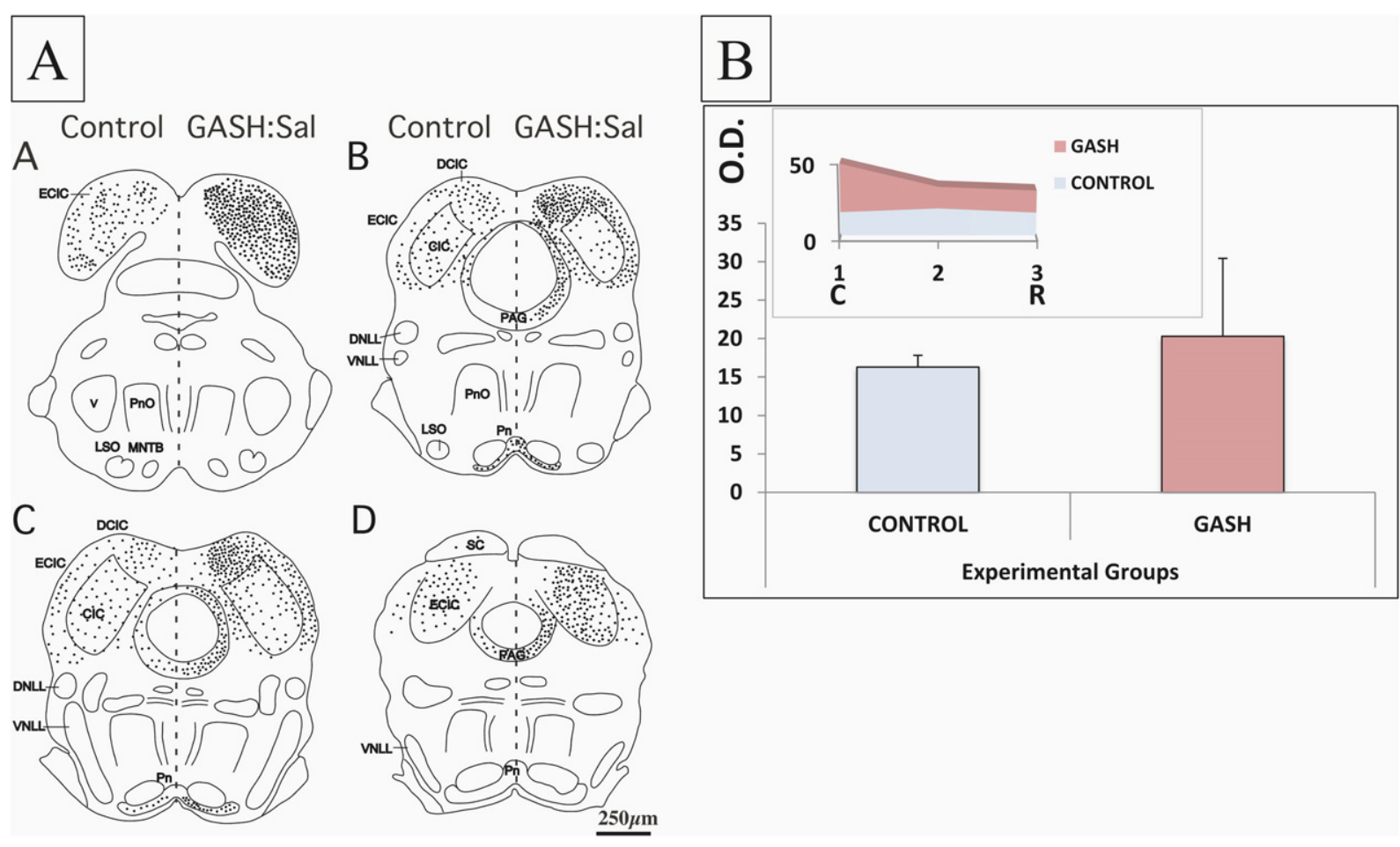

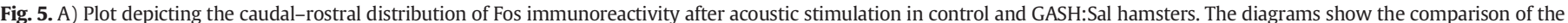

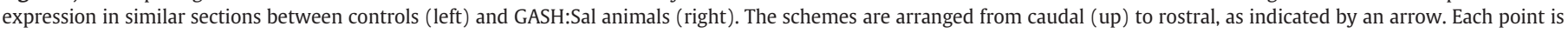

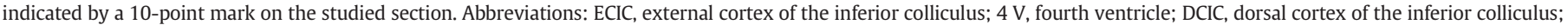

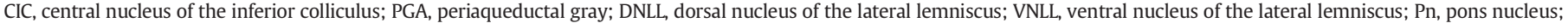

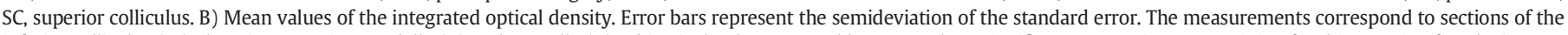

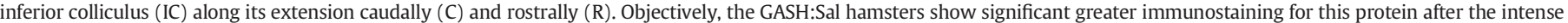
acoustic stimulus $(\mathrm{p}<0.05)$. The inset represents the average values of density of immunostaining through the rostral-caudal axis.

indicates a significant recessive inheritance $(\mathrm{p}<0.01)$ in both $\mathrm{F}_{2}$ and backcrossed generations.

\subsection{AFLP}

Amplified fragment length polymorphism analysis was used to evaluate the genetic diversity between the two strains of Syrian hamsters. The digested products of these two genomic DNAs were obtained by using combined restriction enzymes of EcoRI/MseI. Six primer pairs were selected to generate the AFLP banding pattern for each combination, and the polymorphism rate was calculated based on

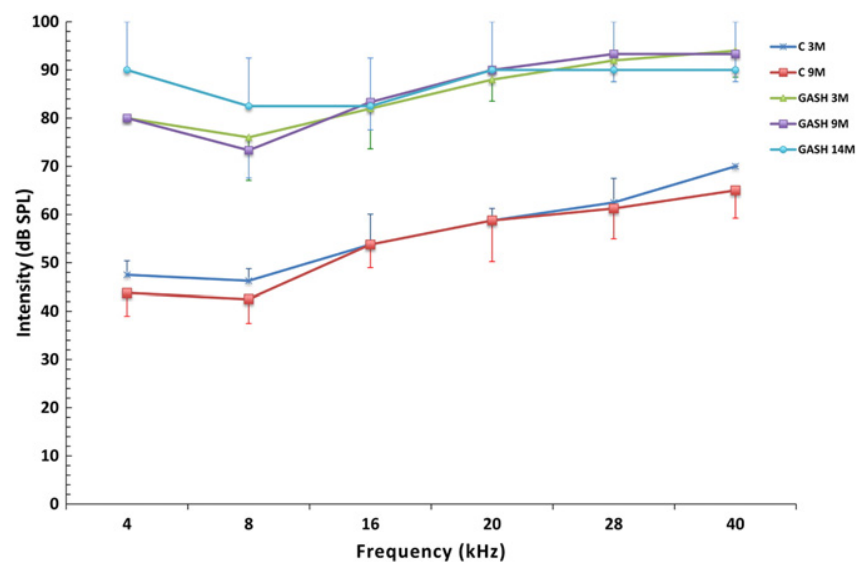

Fig. 6. Control and GASH:Sal audiograms. Audiograms of GASH:Sal hamsters at three, six, and fourteen months old, as well as of control hamsters at three and nine months old, shown as averages with hemistandard deviations. $\mathrm{n}=4$ for controls; for GASH:Sal, $\mathrm{n}=$ 4 at 3 months, $\mathrm{n}=2$ for 6 months, and $\mathrm{n}=1$ for 14 months. the number of scorable polymorphic bands. The primer combinations yielded a total of 660 fragments, with an average of 110 loci per primer combination, and a mean fragment size of $185.97 \mathrm{bp}$. A mean percentage of $49.28 \%$ of the 660 distinguishable bands were polymorphic across all primer combinations.

Based on the approach of Lynch and Milligan [50], genetic diversity and population genetic structure were estimated. Overall expected heterozygosity (HT) was calculated by averaging all loci of the two populations for each primer combination, ranging from $0.3025 \pm$ 0.0122 to $0.3727 \pm 0.0286$ and averaging 0.3381 . Among the six primer combinations, the lowest genetic diversity (HW) was exhibited in E32/ M48 and the highest in E35/M60. In this study, the mean FST across all

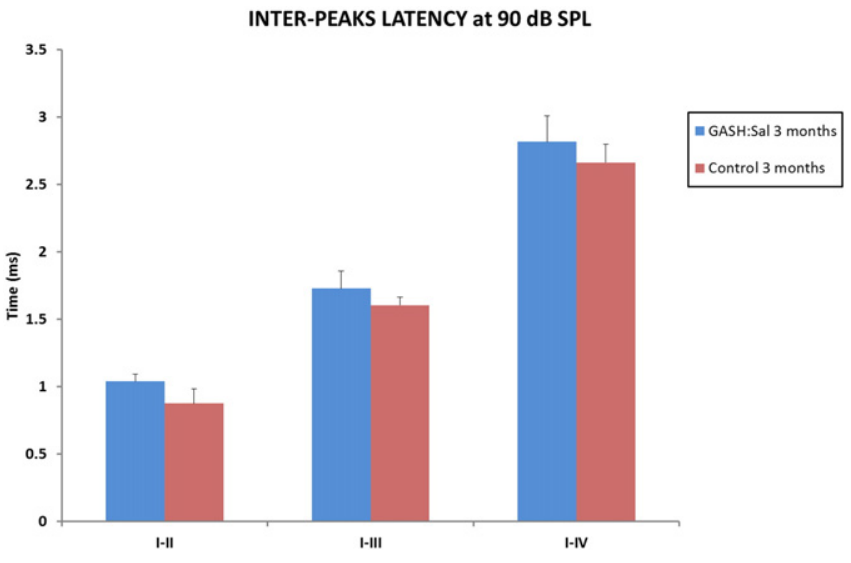

Fig. 7. Interpeak latency (I-II, I-III, and I-IV) in control and GASH:Sal hamsters at 3 months old. $n=4$ controls $+4 \mathrm{GASH} / \mathrm{Sal}$. Histogram shows mean values and hemistandard deviation bars. 
Table 3

Genetic diversity within and between populations of control and GASH:Sal hamsters. Abbreviations: total gene diversity (HT), gene diversity within a population (HW), gene diversity between populations (HB), Wright's fixation index (FST).

\begin{tabular}{lllll}
\hline Primer combinations & HT & HW & HB & FST \\
\hline E32/M48 & 0.3191 & 0.2878 & 0.0310 & 0.0929 \\
E32/M58 & 0.314 & 0.3082 & 0.0059 & 0.0177 \\
E32/M60 & 0.3724 & 0.3245 & 0.0479 & 0.1279 \\
E35/M48 & 0.3478 & 0.2989 & 0.0489 & 0.1326 \\
E35/M58 & 0.3025 & 0.2914 & 0.0111 & 0.0366 \\
E35/M60 & 0.3727 & 0.3413 & 0.0313 & 0.0839 \\
Average & 0.3381 & 0.3087 & 0.0294 & 0.0819 \\
\hline
\end{tabular}

loci was 0.0839 , indicating that approximately $8.4 \%$ of the total genetic variation could be explained by strain differences, whereas the remaining 91.6\% was based on differences among individuals. The lowest FST estimate (0.0177) was from E32/M58 and signifies little genetic differentiation within the populations. The E35/M48 presented the highest value at 0.1329 , indicating a moderate genetic difference within the populations analyzed. Genetic diversity parameters, which include the expected heterozygosity (HT) and average gene diversity within (HW) and between populations (HB), as well as Wright's FST, are shown in Table 3.

Analysis of molecular variance showed that the approximate main variation component (83\%) was attributable to within-population level variance. In terms of interpopulation variability, the overall variability averaged $17 \%$ among the 6 primer combinations. The PhiPT values that represent the genetic differentiation between pairs of populations ranged from 0.064 to 0.239 , significant at 0.079 and 0.0 , respectively. The AMOVA results are listed in Table 4.

To understand the genetic relationships among the two hamster populations, we used AFLP markers to construct phylogenetic trees by the neighbor-joining method using Nei's genetic distance values [49]. A dendrogram (Fig. 8) illustrating the genetic similarity among the individual samples of E35/M48 showed that all the individuals of the control laboratory hamster population were grouped into one major cluster. Additionally, a second major cluster was occupied exclusively by samples of the GASH:Sal population. Two GASH:Sal singletons were joined to the basal branch.

\section{Discussion}

\subsection{Audiogenic susceptibility}

The obtained results indicated an autosomal recessive pattern of inheritance based on the consistent susceptibility of all generations. However, because of the variability in the clinical symptoms, the possibility that other genes may be affecting susceptibility cannot be excluded. Seizure susceptibility has been proposed to be determined by polygenetic inheritance [54], which is influenced by the interaction

\section{Table 4}

Analysis of molecular variance (AMOVA) within and among populations of control and GASH:Sal hamsters. Statistical analysis of the diversity of AFLP between those groups, reflecting the percentage of variation within or among populations. Abbreviations: d.f., degrees of freedom; PhiPT, proportion of variance in the population relative to the total variance; p, probability; pop., population; Var. est., variance estimation.

\begin{tabular}{lrlllllll}
\hline $\begin{array}{l}\text { Primer } \\
\text { comb. }\end{array}$ & d.f. & $\begin{array}{l}\text { Sum of } \\
\text { squares }\end{array}$ & $\begin{array}{l}\text { Mean } \\
\text { squares }\end{array}$ & $\begin{array}{l}\text { Var. } \\
\text { est. }\end{array}$ & $\begin{array}{l}\text { Within } \\
\text { pop. }\end{array}$ & $\begin{array}{l}\text { Among } \\
\text { pop. }\end{array}$ & PhiPT & p \\
\hline E32/M48 & 14 & 148.4 & 32.297 & 11.473 & $84 \%$ & $16 \%$ & 0.157 & 0.001 \\
E32/M58 & 13 & 126.714 & 23.207 & 10.05 & $94 \%$ & $6 \%$ & 0.064 & 0.079 \\
E32/M60 & 9 & 114.3 & 35.05 & 14.276 & $79 \%$ & $21 \%$ & 0.207 & 0.017 \\
E35/M48 & 11 & 179.417 & 51.617 & 18.18 & $78 \%$ & $22 \%$ & 0.219 & 0.002 \\
E35/M58 & 10 & 91.818 & 23.966 & 9.765 & $87 \%$ & $13 \%$ & 0.131 & 0.030 \\
E35/M60 & 13 & 202.429 & 55.533 & 17.558 & $76 \%$ & $24 \%$ & 0.239 & 0.00 \\
Overall & & Total & & & $83 \%$ & $17 \%$ & 0.1695 &
\end{tabular}

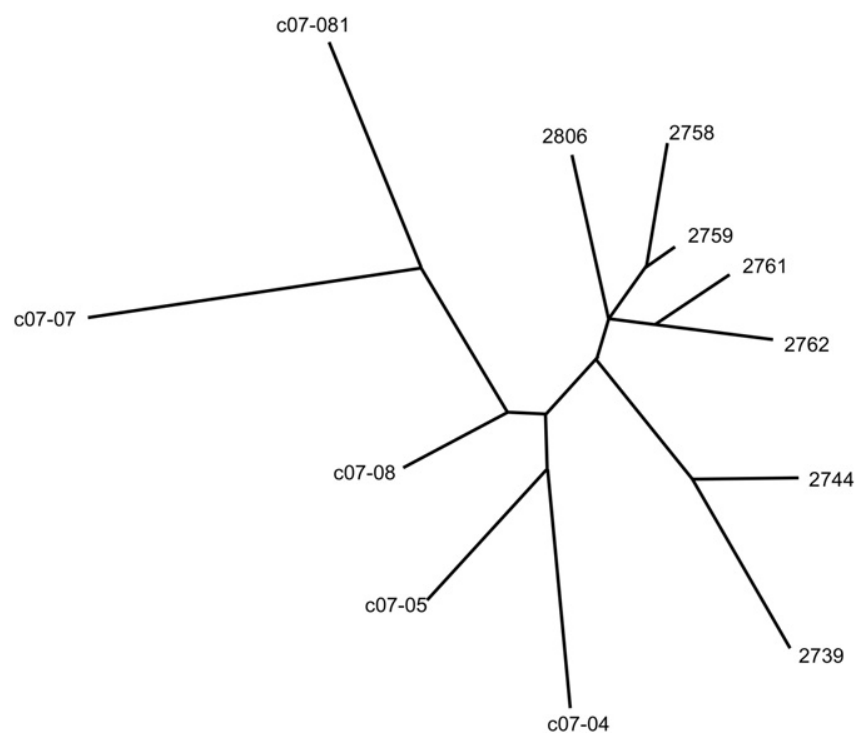

Fig. 8. Genetic variability between control and GASH:Sal individuals. Phylogenetic tree depicting 12 individuals derived from the two initial populations of Mesocricetus auratus. The AFLP was obtained with the E35/M48 combination and the dendrogram based on Nei's genetic distance, with 1000 random permutations. Note that the control and GASH:Sal individuals are grouped in separate branches.

of genes related to the susceptibility, expression, modulation, and temporal expression of seizures.

From the clinical perspective, seizure progression, whether from a genetically susceptible or kindling model, can be divided into several phases: wild running, clonic or tonic or tonic-clonic, and postictal nonreactive [25]. Recently, several anomalies in other behavioral attributes, such as exploratory activity, have been reported [55]. The latency, presence of phases, seizure resolution, and kinetic-postural descriptions have all been utilized as instruments to evaluate audiogenic seizures. Severity depends on several external factors, including the consistency and intensity of the stimulus, as well as internal factors such as an occlusion of the ear. Additionally, innate variables and biological rhythms of each individual must be considered.

Regarding the initial latency phase, we only observed a difference between 30-day-old and 6-month-old GASH:Sal hamsters. Comparing the remaining phases (wild running, convulsions, and stupor) presented by one-month-old animals, there is a stark difference in the clinical manifestations compared to more advanced ages. This finding suggests that at 1 month of age, the auditory system has not completely matured.

The wild running phase, in which the animal runs quickly in an uncontrolled fashion, constitutes the initial phase. This phase is evident in all audiogenic seizures, regardless of the severity afterwards. In some models, this phase manifests as two run cycles. When only one run cycle is present preceding the convulsions, this means there is a seizure with a strong severity index. In our case, having applied a short stimulus (20 s), we were not able to identify the presence of more than one run cycle [56]. In our study, this was the only constant phase in the experimental observations, meeting one of the premises characterizing audiogenic seizure models. The variations in latency of this phase, seen in stimulations performed until 60 days of age, corresponded to a lower threshold for the severe seizure type, when compared with the latencies observed in the genetic models GEPR and WAR [25]. However, after 6 months, an increase in latency was observed; this could indicate a reduced susceptibility, although this finding could also be interpreted as an auditory deficit of genetic origin that caused damage to the afferent system or as intrinsic damage caused by the seizure. The tonic-clonic phase, which follows the wild running phase, is initially characterized in our animals by the presence of an opisthotonic phase, followed by clonic convulsion of the forelimbs and concurrent tonic spasms of the hindlimbs. Animals with a convulsion phase, categorized in our case 
as tonic-clonic or tonic-clonic-tonic, presented latencies of approximately $10 \mathrm{~s}$ for this phase. This fact was taken as further evidence to classify this line as medium-high in the severity index in comparison with the GEPR and WAR models.

The tonic phase is considered the most severe manifestation of the audiogenic seizure. Occasionally, it culminates with the death of the animal, as seen in DBA/2J mice. However, this is not the case with all experimental models. In this phase, a sustained hyperextension of the torso, neck, and extremities is observed. Our animals presented toniclike symptoms as previously described, but in no case did mortality occur. However, mortality after the tonic phase has been described in the GPG:Vall line [38]. In addition, we observed a shortening of the initial tonic-clonic period associated with posterior tonic characteristics. No significant differences were observed in the duration of the convulsive phase, either animals with the exclusively tonic-clonic component or those ending with the tonic phase. In our case, the unreactive postictal phase presented significant differences in its diachronic evolution. First, animals stimulated at 30 days had a shorter average duration of this phase. They also recovered faster than those animals tested at 45 or 60 days, in which these durations were similar. At 6 months, the duration of the stupor phase increased. Neuroanatomical analyses do not show a loss of auditory neurons with aging, leading us to hypothesize a series of molecular changes without a large impact on phenotype. No noteworthy variations were observed between generations. The values for latency and phase duration were quite homogenous. Perhaps the selection conducted in the two lines of reduced genetic heterogeneity eliminated much of the response variability.

In our clinical description, we present evidence of a clear temporal evolution in the susceptibility of these hamsters to display high severity seizures. The most sensitive age studied is 2 months old. It appears that at 6 months, the tendency is inverted again, but the data can also be interpreted as a defect in the afferent pathway that could be causing a loss of auditory capacity in the animals. Notably, the sample of this age was smaller than in the three previous stimulations.

\subsection{Auditory nuclei activated after the seizures}

It is well known that a sudden and intense auditory stimulus can induce the expression of $c$-fos in certain brain areas [57] and therefore can be used as a marker to identify the brain structures involved in several types of experimental seizure, in general, and of audiogenic seizures, in particular [58-63]. In our strain, using Fos protein immunoreactivity, we were able to confirm the involvement of various brainstem nuclei in the onset and development of audiogenic seizures, including nuclei such as the PAG and IC (external and dorsal cortices) and, to a lesser extent, the central nucleus. Densitometric analysis of the IC immunoreactivity against Fos protein showed significant differences between the GASH:Sal and control hamsters. Fos immunoreactivity in the IC after the onset of an acute seizure has also been found in various rat $[61,62$, $64]$ and mice $[65,66]$ models with audiogenic susceptibility. Many studies have demonstrated a critical role for the IC at the onset of the AGS in various lines of susceptible animals [67-76].

The high Fos immunoreactivity in the ECIC is consistent with a key role in triggering the AGS, since this IC subnucleus has outputs, in addition to primary acoustic structures, to subcortical integrative sensorimotor nuclei [77-80]. Our data also showed significant overexpression of the $c$-fos gene in the PAG in the GASH:Sal hamsters, which is consistent with studies in other strains that have AGS (GEPR-9 rats [81], C57BL/6J mice, and DBA/2J mice [66]). This structure is considered to be involved in the onset of both the clonic phases of AGS $[69,81,82]$ and the tonic-clonic [67] phases.

The cuneiform nucleus and the pontine nucleus (Pn) are other structures in the brainstem presenting increased Fos immunoreactivity, although to a lesser degree than the IC. According to Klein [65], these regions may receive direct or indirect inputs from the ECIC and may be involved in tonic seizure propagation $[62,63]$. In short, we can say that the immunoreactivity of the Fos protein observed after an acute audiogenic seizure in the brainstem of the GASH:Sal hamster strain is very similar to that obtained in other audiogenic strains, using a similar protocol.

\section{3. $A B R$}

Our results in GASH:Sal hamsters show that although sound signal transmission occurs in the auditory pathway, these animals have significant hearing loss. This characteristic is common in many rodents exhibiting audiogenic seizures $[83,84]$. These animals tend to show a reduction in their $A B R$ response latencies, even to stimulations at $8 \mathrm{kHz}$, which is the optimal frequency for hearing in rats and most rodents [85]. Mice prone to audiogenic seizures have shown increased excitability upon hearing, which is characterized by higher amplitude of the ABR in the cochlear nucleus and inferior colliculus at intensities above the hearing threshold [17].

In rats genetically prone to epilepsy (GEPR), the susceptibility to AGS is associated with higher ABR thresholds and with increased latency of waves [86].

Changes in the latencies between the peaks of ABR suggest the presence of additional alterations in the auditory pathway of susceptible animals that make them susceptible to AGS, particularly in waves IV-V, which may involve the IC [87]. In AGS-susceptible rats, the tonotopic IC bands $[88,89]$ suggest hyperexcitability of afferent and/or intrinsic IC as well as a change in the functional organization of the central auditory pathway.

A correlation between hearing loss and susceptibility to seizures seems to be a constant in animals with audiogenic seizures. Thus, chickens with audiogenic seizures (White Leghorn) exhibit altered ABRs, with normal early peaks and late components with increased latency and decreased amplitude [90]; Frings Mgr1 mutant mice (which have a mutation in the gene MASS1) also show a mild-to-moderate deterioration in hearing [91], which appears during early postnatal development and continues into old age. Similarly, cats with penicillininduced epilepsy show increases in all ABR components [92].

\subsection{Genetic variability of GASH:Sal hamsters}

Syrian hamsters are commonly used in biomedical research, including the experimental induction of tumors, infectious diseases, and other pathological research. Despite their popularity, few studies have reported the identification of genetic characteristics of these animals [93-95]. Published studies show that the levels of genetic differentiation in wild golden Syrian hamsters and laboratory strains are low, confirming that all surviving members of the species $M$. auratus are derived from a limited number of parents [93]. Recently, the analysis of microsatellite loci, used to establish a linkage analysis and to trace patterns of inheritance among populations of wild and laboratory golden hamsters, has shown a reduction in the genetic variability of the population kept in laboratories [96]. This reduction is a consequence of the rupture of Hardy-Weinberg equilibrium in laboratory populations, as well as the effect of inbreeding, because both lead to increased homozygosity in a population.

Because of the lack of genetic data for the species M. auratus, we used the AFLP technique to determine the genetic variation between the control golden hamsters and the GASH:Sal strain. This method has several advantages over other genomic fingerprint techniques and allowed us to perform multiple comparisons of DNA regions distributed across an entire genome, without the need for any prior knowledge of the sequence [97]. The genetic diversity revealed in this study is highly relevant to the recently reported AFLP characterization of inbred strains of mammals [98-104].

More importantly, this study represents the first screening of genetic variability at the genomic level in different lines of laboratory hamsters. Therefore, it may constitute a starting point for further research involving the use of AFLP markers to relate the genetics of different laboratory 
strains of hamsters to their phenotypic differences because AFLPs are based on mutations that cause phenotypic variation by modulating gene expression and function.

In recent decades, increasing evidence has indicated that complex genetic factors contribute to a predisposition to epilepsy. Given this predisposition, likely determined by multiple genes, genetically susceptible animal models of epilepsy appear to resemble more closely the generalized epilepsy in humans than do models in which seizures are experimentally induced. The successful detection of strain-specific polymorphisms may not only allow for an effective analysis of genetic variation between populations of this species but also raises the prospect of detecting the genomic markers of epilepsy. Additionally, considering the lack of genomic information regarding the GASH:Sal strain, use of the AFLP technique may allow for the genetic characterization of this strain, with significant genetic differences of approximately $17 \%$ between this strain and the control population. Additional molecular studies are needed to find the differential genetic substrate that makes these animals susceptible to suffering epileptic seizures, which are transmitted by autosomal recessive inheritance.

\subsection{Relevance of the model}

Although certain motor components of AGS (i.e., wild running) are not commonly present in human generalized tonic-clonic seizures (GTCS), we strongly believe this to be a reliable animal model of epilepsy as substantiated by our own electroencephalographic recordings [105] of a conspicuous progressive seizure profile similar to those exhibited by other models of inherited AGS susceptibility and those exhibited during human GTCS.

The epileptic syndrome displayed by GASH:Sal can be classified within the sensory-elicited human reflex epilepsies as a type of sound-induced epilepsy related to musicogenic epilepsies [106] or telephone-induced seizures [107] appearing in the young adult. Although perhaps GASH:Sal seizures would be closest to the so-called "reflex myoclonic epilepsy of infancy". This refers to syndromes occurring in infants (aged 6-21 months) presenting generalized myoclonic seizures as reflex responses to auditory and/or tactile stimuli [108]. These epilepsies can be considered less severe than the GASH:Sal syndrome since some patients show spontaneous remission. The GASH: Sal epilepsy could also be related to Dravet's syndrome [109] or severe myoclonic epilepsy of infancy (associated with mutations of the sodium channel subunit coding genes SCN1A) [110]. It is also connected to generalized (genetic) epilepsy with febrile seizure plus [111]. These syndromes share their neonatal appearance and their genetic origin with the GASH:Sal seizures.

Finally, in addition to being able to reliably reproduce the objective symptoms and EEG features of the epilepsy syndrome, it is also able to respond to different antiepileptic drugs (AEDs), such as phenobarbital, valproic acid, and levetiracetam [112], so the GASH:Sal is a reliable animal model of epilepsy.

\section{Conclusions}

The GASH:Sal hamster strain presents susceptibility to audiogenic seizures with an autosomal recessive inheritance pattern.

Audiogenic seizures are characterized by a short latency period after auditory stimulation, followed by wild running, a convulsive phase, and finally stupor, with origin in the brainstem and with IC and PAG playing additional key roles.

Additionally, GASH:Sal hamsters show a significant hearing deficit, and from a phylogenetic perspective, the GASH:Sal strain shows differences of approximately $17 \%$ compared to the wild-type $M$. auratus.

They have a seizure profile similar to those exhibited by other models of inherited AGS susceptibility and can be considered a reliable genetic model of epilepsy.

\section{Acknowledgments}

The authors would like to thank Dr. Carlos de Cabo and Dr. LópezPoveda for very helpful suggestions. They are also very grateful to the Non-invasive Neurofunctional Evaluation Service (ENNI) of the Alberto Sols Biomedical Research Institute (CSIC, Madrid) for the auditory evaluation of the strain. This study was supported by the Spanish JCyL Grants (\#SAN/191/SA24/06 and \#SA023A12-2).

\section{Conflict of interest}

The authors certify that they have no affiliations with or involvement in any organization or entity with any financial interest (such as honoraria; educational grants; participation in speakers' bureaus; membership, employment, consultancies, stock ownership, or other equity interest; or expert testimony or patent-licensing arrangements) or nonfinancial interest (such as personal or professional relationships, affiliations, knowledge, or beliefs) in the subject matter or materials discussed in this manuscript.

\section{References}

[1] Jobe PC, Laird HE. Neurotransmitter abnormalities as determinants of seizure susceptibility and intensity in the genetic models of epilepsy. Biochem Pharmacol 1981;30(23):3137-44.

[2] Kandratavicius L, Balista PA, Lopes-Aguiar C, Ruggiero RN, Umeoka EH, GarciaCairasco N, et al. Animal models of epilepsy: use and limitations. Neuropsychiatr Dis Treat 2014;10:1693-705.

[3] Frankel WN. Genetics of complex neurological disease: challenges and opportunities for modeling epilepsy in mice and rats. Trends Genet 2009;25:361-7.

[4] Serikawa T, Mashimo T, Kuramoto T, Voigt B, Ohno Y, Sasa M. Advances on genetic rat models of epilepsy. Exp Anim 2015;64(1):1-7.

[5] Faingold CL, Marcinczyk MJ, Casebeer DJ, Randall ME, Arnerić SP, Browning RA, et al. GABA in the inferior colliculus plays a critical role in control of audiogenic seizures. Brain Res 1994;640(1-2):40-7.

[6] Skradski SL, White HS, Ptacek LJ. Genetic mapping of a locus (mass1) causing audiogenic seizures in mice. Genomics 1998;49(2):188-92.

[7] Löscher W. Animal models of epilepsy for the development of antiepileptogenic and disease-modifying drugs. A comparison of the pharmacology of kindling and post-status epilepticus models of temporal lobe epilepsy. Epilepsy Res 2002; 50(1-2):105-23.

[8] Yagi H, Takamura Y, Yoneda T, Konno D, Akagi Y, Yoshida K, et al. Vlgr1 knockout mice show audiogenic seizure susceptibility. J Neurochem 2005;92(1):191-202.

[9] Krushisky LV, Molodkina LN, Fless DA, Dobrokhotova LP, Steshenko AP, Semiokhina AF, et al. The functional state of the brain during sonic stimulation. In: Welch BL, Welch AS, editors. Physiological effects of noise. New York: Plenum Press; 1970. p. 151-8.

[10] Maxson SC, Cowen JS. Electroencephalographic correlates of the audiogenic seizure response of inbred mice. Physiol Behav 1976;16(5):623-9.

[11] Seyfried TN. Audiogenic seizures in mice. Fed Proc 1979;38(10):2399-404.

[12] Kesner RP. Subcortical mechanisms of audiogenic seizures. Exp Neurol 1966;15(2): 192-205.

[13] Willot JF, Lu SM. Midbrain pathways of audiogenic seizures in DBA/2 mice. Exp Neurol 1980;70:288-99.

[14] Browning RA. Neuroanatomical localization of structures responsible for seizures in the GEPR: lesion studies. Life Sci 1986;39(10):857-67.

[15] Wada JA, Terao A, White B, Jung E. Inferior colliculus lesion and audiogenic seizure susceptibility. Exp Neurol 1970;28:326-32.

[16] McCown T], Greenwood RS, Frye GD, Breese GR. Electrically elicited seizures from the inferior colliculus: a potential site for the genesis of epilepsy? Exp Neurol 1984;86(3):527-42.

[17] Saunders JC, Bock GR, James R, Chen CS. Effects of priming for audiogenic seizure on auditory evoked responses in the cochlear nucleus and inferior colliculus of BALB-c mice. Exp Neurol 1972;37(2):388-94.

[18] Sánchez-González MA. Estudio de las neuronas olivococleares del tronco de encéfalo en el hámster (Mesocricetus auratus) normal y en el hámster con convulsiones audiogénicas de origen genético de la cepa GPG/Vall. [Tesina] Universidad de Salamanca; 1999.

[19] Faingold CL. Role of GABA abnormalities in the inferior colliculus pathophysiology - audiogenic seizures. Hear Res 2002;168:223-37.

[20] Naruse HH, Kato M, Kurokawa M, Haba R, Yabe T. Metabolic defects in a convulsive strain of mouse. J Neurochem 1960;5(4):359-69.

[21] McGeer PL, McGeer EG, Wada JA. Glutamic acid decarboxylase in Parkinson's disease and epilepsy. Neurology 1971;21(10):1000-7.

[22] Ribak CE, Byun MY, Ruiz GT, Reiffenstein RJ. Increased levels of amino acid neurotransmitters in the inferior colliculus of the genetically epilepsy-prone rat. Epilepsy Res 1988;2(1):9-13.

[23] Roberts RC, Ribak CE, Oertel WH. Increased numbers of GABAergic neurons occur in the inferior colliculus of an audiogenic model of genetic epilepsy. Brain Res 1985;361(1-2):324-38. 
[24] Ribak CE. An abnormal GABAergic system in the inferior colliculus provides a basis for audiogenic seizures in genetically epilepsy-prone rats. Epilepsy Behav 2015. http://dx.doi.org/10.1016/j.yebeh.2015.02.024

[25] Ross KC, Coleman JR. Developmental and genetic audiogenic seizure models: behavior and biological substrates. Neurosci Biobehav Rev 2000;24(6):639-53 [Review]

[26] Huxtable RJ, Laird HE. The prolonged anticonvulsant action of taurine on genetically determined seizure-susceptibility. Can J Neurol Sci 1978;5(2):215-21.

[27] Laird HE, Huxtable RJ. In: Barbeau A, Huxtable RJ, editors. Taurine and neurological disorders. New York: Raven Press; 1978. p. 339.

[28] Parry H. Canine hysteria and wheat. Lancet 1948;3.

[29] Faingold CL. Emergent properties of CNS neuronal networks as targets for pharmacology: application to anticonvulsant drug action. Prog Neurobiol 2004;72(1): 55-85.

[30] Henry KR. Audiogenic seizure susceptibility induced in C57BL-6] mice by prior auditory exposure. Science 1967;158(3803):938-40.

[31] Poletaeva II, Surina NM, Kostina ZA, Perepelkina OV, Fedotova IB. The KrushinskyMolodkina rat strain: the study of audiogenic epilepsy for 65 years. Epilepsy Behav 2015. http://dx.doi.org/10.1016/j.yebeh.2015.04.072.

[32] Reigel CE, Dailey JW, Jobe PC. The genetically epilepsy-prone rat: an overview of seizure-prone characteristics and responsiveness to anticonvulsant drugs. Life Sci 1986;39(9):763-7.

[33] Doretto MC, Fonseca CG, Lôbo RB, Terra VC, Oliveira JA, Garcia-Cairasco N. Quantitative study of the response to genetic selection of the Wistar audiogenic rat strain (WAR). Behav Genet 2003;33(1):33-42.

[34] Seyfried TN, Glaser GH. A review of mouse mutants as genetic models of epilepsy. Epilepsia 1985;26(2):143-5.

[35] Yoon CH, Peterson JS, Corrow D. Spontaneous seizures: a new mutation in Syrian golden hamsters. J Hered 1976;67(2):115-6.

[36] Fisher JE, Iturrian WB. The spontaneous seizures genotype sz in hamsters as a disease model of benzodiazepine receptor deficits. Soc Neurosci Abstr 1984;10: 1065.

[37] Löscher W, Fisher JE, Schmidt D, Fredow G, Honack D, Iturrian WB. The sz mutant hamster: a genetic model of epilepsy or of paroxysmal dystonia? Mov Disord 1989;4(3):219-32.

[38] Soria MA, Macias JA, Aguirre A, Gómez P, Gómez ME. Epilepsia audiógena en una cepa endogámica de hámster dorado (Mesocricetus auratus). Rev Esp Epilepsia 1987;2(1):27-33.

[39] Gil-Verona JA, Gómez M, Gómez P, Macías J, García-Atarés N. Comportamiento morfológico de la porción troncoencefálica del sistema acústico en hámsters que padecen epilepsia audiógena. Rev Esp Epilepsia 1991;6:85-95.

[40] Macías J, Gil-Verona JA, Franco M. Estudio neurofisiológico del ritmo nictameral en una cepa endogámica de hámsters dorados con epilepsia audiógena (II). Rev Neurofisiol Clín 1992;5-1:19-22.

[41] Schreiber RA, Lehmann A, Ginsburg BE, Fuller JI. Development of susceptibility to audiogenic seizures in $\mathrm{DBA} / 2 \mathrm{~J}$ and $\mathrm{Rb}$ mice: toward a systematic nomenclature of audiogenic seizure levels. Behav Genet 1980;10(6).

[42] García-Cairasco N, Sabbatini RM. Role of the substantia nigra in audiogenic seizures: a neuroethological analysis in the rat. Braz J Med Biol Res 1983;16(2): 171-83.

[43] Gómez-Nieto R, Rubio ME, López DE. Cholinergic input from the ventral nucleus of the trapezoid body to cochlear nucleus of the trapezoid to cochlear root neurons in rats. J Comp Neurol 2008;506:452-68.

[44] Fuentes-Santamaría V, Cantos R, Alvarado JC, García-Atarés N, López DE. Morphological and neurochemical abnormalities in the auditory brainstem of the genetically epilepsy-prone hamster (GPG/Vall). Epilepsia 2005;46(7):1027-46.

[45] Morin LP, Wood RI. A stereotaxic atlas of the golden hamster brain. San Diego: Academic Press; 2001.

[46] Hormigo S, Horta-Junior JAC, Gómez-Nieto R, López DE. The selective neurotoxin DSP-4 impairs the noradrenergic projection from the locus coeruleus to the inferior colliculus in rats. Front Neural Circ 2012;6(41) 1-14.

[47] Vos P, Hogers R, Bleeker M, Reijans M, van de Lee T, Hornes M, et al. AFLP: a new technique for DNA fingerprinting. Nucleic Acids Res 1995;23(21):4407-14.

[48] Vekemans M. Parental age and genetic risks for the offspring. Gynecol Obstet Fertil 2002;30(10):831-3.

[49] Nei M. Estimation of average heterozygosity and genetic distance from a small number of individuals. Genetics 1978;89(3):583-90.

[50] Lynch M, Milligan BG. Analysis of population genetic structure with RAPD markers. Mol Ecol 1994;3(2):91-9.

[51] Wright S. The genetical structure of populations. Ann Eugen 1951;15:323-54.

[52] Nei M, Li WH. Mathematical model for studying genetic variation in terms of restriction endonucleases. Proc Natl Acad Sci U S A 1979;76(10):5269-73.

[53] Saitou N, Nei M. The neighbor-joining method: a new method for reconstructing phylogenetic trees. Mol Biol Evol 1987;4(4):406-25.

[54] Buchhalter JR. Animal models of inherited epilepsy. Epilepsia 1993;34(Suppl. 3): S31-41.

[55] Garcia-Cairasco N, Oliveira JA, Wakamatsu H, Bueno ST, Guimaraes FS. Reduced exploratory activity of audiogenic seizures susceptible Wistar rats. Physiol Behav 1998;64:671-4.

[56] Jobe PC, Picchioni AL, Chin L. Role of brain 5-hydroxytryptamine in audiogenic seizure in the rat. Life Sci 1973;13:1-13.

[57] Bullitt E. Expression of $c$-fos-like protein as a marker for neuronal activity following noxious stimulation in the rat. J Comp Neurol 1990;296:517-30.

[58] Douglas RM, Dragunow M, Robertson HA. High-frequency discharge of dentate granule cells, but not long-term potentiation, induces $c$-fos protein. Brain Res 1988;464:259-62.
[59] Daval JL, Nakajima T, Gleiter CH, Post RM, Marangos PJ. Mouse brain c-fos mRNA distribution following a single electroconvulsive shock. J Neurochem 1989;52: 1954-7.

[60] Le Gal La Salle G, Naquet R. Audiogenic seizures evoked in DBA/2 mice induce c-fos oncogene expression into subcortical auditory nuclei. Brain Res 1990; 518:308-12.

[61] Snyder-Keller AM, Pierson MG. Audiogenic seizures induce $c$-fos in a model of developmental epilepsy. Neurosci Lett 1992;135:108-12.

[62] Clough RW, Eells JB, Browning RA, Jobe PC. Seizures and proto-oncogene expression of Fos in the brain of adult genetically epilepsy-prone rats. Exp Neurol 1997; 146:341-53.

[63] Samoriski GM, Piekut DT, Applegate CD. Regional analysis of the spatial patterns of Fos induction in brain following flurothyl kindling. Neuroscience 1998;84: 1209-22.

64] Simler S, Hirsch E, Danober L, Motte J, Vergnes M, Marescaux C. C-fos expression after single and kindled audiogenic seizures in Wistar rats. Neurosci Lett 1994; 175:58-62.

[65] Klein BD, Fu YH, Ptacek LJ, White HS. C-fos immunohistochemical mapping of the audiogenic seizure network and tonotopic neuronal hyperexcitability in the inferior colliculus of the Frings mouse. Epilepsy Res 2004;62:13-25.

[66] Garcia-Cairasco N. A critical review on the participation of inferior colliculus in acoustic-motor and acoustic-limbic networks involved in the expression of acute and kindled audiogenic seizures. Hear Res 2002;168(1-2):208-22.

[67] Faingold CL. Neuronal networks in the genetically epilepsy-prone rat. Adv Neurol 1999;79:311-21.

[68] Raisinghani M, Faingold CL. Identification of the requisite brain sites in the neuronal network subserving generalized clonic audiogenic seizures. Brain Res 2003; 967:113-22.

[69] Ishida Y, Nakahara D, Hashiguchi H, Nakamura M, Ebihara K, Takeda R, et al. Fos expression in GABAergic cells and cells immunopositive for NMDA receptors in the inferior and superior colliculi following audiogenic seizures in rats. Synapse 2002;46:100-7.

[70] Browning RA. Anatomy of generalized convulsive seizures. In: Malafosse A, Genten P, Hirsch E, Marescaux C, Broglin D, Bernasconi R, editors. Idiopathic generalized epilepsies: clinical, experimental and genetic aspects. London: Libbey; 1994. p. 399-413.

[71] Faingold CL, Riaz A. Ethanol withdrawal induces increased firing in inferior colliculus neurons associated with audiogenic seizure susceptibility. Exp Neurol $1995 ; 132: 91-8$

[72] Li Y, Evans MS, Faingold CL. Inferior colliculus neuronal membrane and synaptic properties in genetically epilepsy-prone rats. Brain Res 1994;660:232-40.

[73] Ribak CE, Morin CL. The role of the inferior colliculus in a genetic model of audiogenic seizures. Anat Embryol (Berl) 1995;191:279-95.

[74] Sakamoto T, Niki H. Acoustic priming lowers the threshold for electrically induced seizures in mice inferior colliculus, but not in the deep layers of superior colliculus. Brain Res 2001;898:358-63.

[75] Pierson M, Snyder-Keller A. NMDA receptor-dependent epileptogenesis in developing inferior colliculus. Epilepsy Res Suppl 1992;9:371-82.

[76] Yang L, Long C, Faingold CL. Neurons in the deep layers of superior colliculus are a requisite component of the neuronal network for seizures during ethanol withdrawal. Brain Res 2001:920:134-41.

[77] Ribak CE, Khurana V, Lien NT. The effect of midbrain collicular knife cuts on audiogenic seizure severity in the genetically epilepsy-prone rat. J Hirnforsch 1994;35: 303-11.

[78] Merrill MA, Clough RW, Jobe PC, Browning RA. Role of the superior colliculus and the intercollicular nucleus in the brainstem seizure circuitry of the genetically epilepsy-prone rat. Epilepsia 2003;44:305-14.

[79] Chakravarty DN, Faingold CL. Aberrant neuronal responsiveness in the genetically epilepsy-prone rat: acoustic responses and influences of the central nucleus upon the external nucleus of inferior colliculus. Brain Res 1997;761: 263-70.

[80] Chakravarty DN, Faingold CL. Differential roles in the neuronal network for audiogenic seizures are observed among the inferior colliculus subnuclei and the amygdala. Exp Neurol 1999;157:135-41.

[81] N'Gouemo P, Faingold CL. Periaqueductal gray neurons exhibit increased responsiveness associated with audiogenic seizures in the genetically epilepsy-prone rat. Neuroscience 1998;84:619-25.

[82] Yang L, Long C, Evans MS, Faingold C. Ethanol withdrawal results in aberrant membrane properties and synaptic responses in periaqueductal gray neurons associated with seizure susceptibility. Brain Res 2002;957:99-108.

[83] Henry KR, Saleh M. Recruitment deafness: functional effect of priming-induced audiogenic seizures in mice. J Comp Physiol Psychol 1973;84:430-5.

[84] Penny JE, Brown RD, Hodges KB, Kupetz SA, Glenn DW, Jobe PC. Cochlear morphology of the audiogenic-seizure susceptible (AGS) or genetically epilepsy prone rat (GEPR). Acta Otolaryngol 1983;95 1-12.

[85] Coleman JR, Campbell D, Cooper WA, Welsh MG, Moyer J. Auditory brainstem responses after ovariectomy and estrogen replacement in rat. Hear Res 1994;80: 209-15.

[86] Faingold CL, Walsh EJ, Maxwell JK, Randall ME. Audiogenic seizure severity and hearing deficits in the genetically epilepsy-prone rat. Exp Neurol 1990;108: 55-60.

[87] Funai H, Funasaka S. Experimental study on the effect of inferior colliculus lesions upon auditory brainstem response. Audiology 1983;22:9-19.

[88] Faingold CL, Gehlbach G, Travis MA, Caspary DM. Inferior colliculus neuronal response abnormalities in genetically epilepsy-prone rats: evidence for a deficit of inhibition. Life Sci 1986;39:869-78. 
[89] Pierson M, Snyder-Keller A. Development of frequency-selective domains in inferior colliculus of normal and neonatally noise-exposed rats. Brain Res 1994; 636:55-67.

[90] Beck MM, Brown-Borg HM, Jones TA. Peripheral and brainstem auditory function in paroxysmal (px) White Leghorn chicks. Brain Res 1987;406:93-8.

[91] Klein BD, Fu YH, Ptacek LJ, White HS. Auditory deficits associated with the frings mgr1 (mass1) mutation in mice. Dev Neurosci 2005;27:321-32.

[92] Burchiel KJ, Myers RR, Bickford RG. Visual and auditory evoked responses during penicillin-induced generalized spike-and-wave activity in cats. Epilepsia 1976;17: 293-311.

[93] McGuire KL, Duncan WR, Tucker PW. Syrian hamster DNA shows limited polymorphism at class I-like loci. Immunogenetics 1985;22:257-68.

[94] Watkins DI, Chen ZW, Hughes AL, Lagos A, Lewis Jr AM, Shadduck JA, et al. Syrian hamsters express diverse MHC class I gene products. J Immunol 1990;145: 3483-90.

[95] Oduru S, Campbell JL, Karri S, Hendry WJ, Khan SA, Williams SC. Gene discovery in the hamster: a comparative genomics approach for gene annotation by sequencing of hamster testis cDNAs. BMC Genomics 2003;4:22

[96] Neumann K, Michaux J, Lebedev V, Yigit N, Colak E, et al. Molecular phylogeny of the Cricetinae subfamily based on the mitochondrial cytochrome b and 12S rRNA genes and the nuclear vWF gene. Mol Phylogenet Evol 2006;39:135-48.

[97] Mueller UG, Wolfenbarger LL. AFLP genotyping and fingerprinting. Trends Ecol Evol 1999;14:389-94.

[98] Ajmone-Marsan P, Valentini A, Cassandro M, Vecchiotti-Antaldi G, Bertoni G, Kuiper M. AFLP markers for DNA fingerprinting in cattle. Anim Genet 1997;28: 418-26.

[99] Ajmone-Marsan P, Negrini R, Milanesi E, Bozzi R, Nijman IJ, Buntjer JB, et al. Genetic distances within and across cattle breeds as indicated by biallelic AFLP markers. Anim Genet 2002;33:280-6.

[100] Kim KS, Jeong HW, Park CK, Ha JH. Suitability of AFLP markers for the study of genetic relationships among Korean native dogs. Genes Genet Syst 2001;76:243-50.
[101] Nijman IJ, Bradley DG, Hanotte O, Otsen M, Lenstra JA. Satellite DNA polymorphisms and AFLP correlate with Bos indicus-taurus hybridization. Anim Genet 1999;30:265-73.

[102] Otsen M, den Bieman M, Kuiper MT, Pravenec M, Kren V, Kurtz TW, et al. Use of AFLP markers for gene mapping and QTL detection in the rat. Genomics 1996;37:289-94.

[103] Ovilo C, Cervera MT, Castellanos C, Martinez-Zapater JM. Characterization of Iberian pig genotypes using AFLP markers. Anim Genet 2000;31:117-22.

[104] Prochazka M, Walder K, Xia J. AFLP fingerprinting of the human genome. Hum Genet 2001;108:59-65.

[105] Carballosa-Gonzalez MM, Muñoz LJ, López-Alburquerque T, Pardal-Fernández JM Nava E, de Cabo C, et al. EEG characterization of audiogenic seizures in the hamster strain GASH:Sal. Epilepsy Res 2013;106(3):318-25.

[106] Pittau F, Tinuper P, Bisulli F, Naldi I, Cortelli P, Bisulli A, et al. Videopolygraphic and functional MRI study of musicogenic epilepsy. A case report and literature review. Epilepsy Behav 2008;13:685-92.

[107] Michelucci R, Gardella E, de Haan GJ, Bisulli F, Zaniboni A, Cantalupo G, et al. Telephone induced seizures: a new type of reflex epilepsy. Epilepsia 2004;45(3): 280-3.

[108] Verrotti A, Matricardia S, Capovilla G, D'Egidio C, Cusmai R, Romeo A, et al. Reflex myoclonic epilepsy in infancy: a multicenter clinical study. Epilepsy Res 2013; 103:237-44.

[109] Dravet C. Les epilepsies graves de l'enfant. Vie Med 1978;8:543-8.

[110] Yamakawa K. Molecular basis of severe myoclonic epilepsy in infancy. Brain Dev 2009;31(5):401-4.

[111] Herini ES, Gunadi, Harahapa ISK, Yusoffa S, Morikawa S, Patria SY, et al. Generalized epilepsy with febrile seizures plus (GEFS +) spectrum: clinical manifestations and SCN1A mutations in Indonesian patients. Epilepsy Res 2010;90(1-2):132-9.

[112] Barrera-Bailón B, Oliveira JAC, López DE, Muñoz de la Pascua LJ, Garcia-Cairasco N Sancho C. Pharmacological and neuroethological study of three antiepileptic drugs in the genetic audiogenic seizure hamster (GASH:Sal). Epilepsy Behav 2013;28(3): 413-25. 